\title{
Kitap Tanitma:
}

LEVENT DUMAN, “Vatan” $n$ Son Parças Hatay'daki Uluslaştrma Politikalar, İletişim Yayınları, Istanbul 2016, $456 \mathrm{~s}$.

Yirminci yüzyll Türkiye ve Suriye'si hakkında yazılmış hacimli bir literatür bulunmasına rağmen 1918-1950 dönemi İskenderun Sancağı, Hatay Devleti ve Türkiye'nin Hatay ili konulannın tarihçilerin yoğun ilgisini çektiği pek söylenemez. Bu alanda mevcutlara ilaveten daha nitelikli eserlere ihtiyaç duyulduğu bir gerçektir. Selçuk Üniversitesinde Yardımcı Doçent Levent Duman'ın Ocak 2016'da yayınlanan “Vatan"ın Son Parçası Hatay'daki Uluslaşturma Politikalan adlı kitabında iki dünya savaşı arası yıllarında Fransız manda yönetimindeki İskenderun Sancağı hakkındaki Türk-Fransız uyuşmazhğının gelişimi ve nihai çözümünün irdelenmesiyle sınırlı kalınmayıp ağırlıkłı ve daha geniş olarak yörenin tarihçesi, yapısal özellikleri ve iç dinamiklerine yer verilmektedir. Sancak'taki çeşitli topluluklar arasındaki güç dengesi ve gerilimler üzerinde önemle durulmaktadır. Kitap Marmara Úniversitesinde Profesör Günay Göksu Özdoğan'ın danışmanlığında hazırlanan doktora tezinin bazı kısaltmalar ve yeni eklemeler yapılmak suretiyle gözden geçirilmiş şeklidir.

Çalışma önsöz ve teşekkür, giriş, yedi bölüm, iki ek, kaynakça ve dizinden meydana gelmektedir. Bölümler sırasıyla "Hatay'ın Siyasi Tarihi ve Sosyal-Ekonomik-Kültürel Yapısı", "Fransız Manda Döneminde Idari Yapı ve Yerel Topluluklar (1918-1936)", "İskenderun Sancağında Türkiye Bağının ve Türklüğün Korunması (1918-1936)", "Hatay'ın Türklüğü Zemininde Uluslararası Meşruiyet Arayışı (1936-1938)", "Ulusçuluklar Mücadelesinde Yeni Arena: Seçmen Yazılımı ve Seçimler (1936-1938)", "Hatay Devleti Dönemi: Son Sürat Uluslaşturma (2 Eylül 1938-29 Haziran 1939)", "Vilayet Dönemi: Yeninin Vatana Eklenmesi" ve "Sonuç Yerine: Geçmişten Günümüze Hatay" başlıkları taşımaktadır. Metinde kronolojik sırayla başlıca şu konular üzerinde durulmaktadır: Bölgenin sosyoekonomik ve kültürel özellikleri, Birinci Dünya Savaşından Hatay Devletine uluslararası ilişkiler; Fransız işgaline direniş hareketi, Manda döneminde yerel topluluklar ve yönetim; Yeni sınırlar, sınır ötesi ilişkiler, karşıt ulusçuluklara giden süreç; Yeni bir ulusal mesele: İskenderun Sancağı, Sancak'ta çoğunluk sağlama çabaları, Milletler Cemiyeti kararlarının yansımaları; Seçmen yazılımı öncesi Sancak'taki durum ve Türkiye'nin tutumu, Milletler Cemiyeti Seçim Komisyonu idaresinde seçmen yazılımları, Türk-Fransız Seçim Komisyonu ve Türkiye'nin seçim zaferi; Hatay Devletinde Türkiye'nin etkisi ve Türklük vurgusu, Suriye'den uzaklaşıp Türkiye'ye yakınlaşmaya dönük politikalar, Hatay Devletinde yerel topluluklar; Hatay vilayetinin kuruluşu, yeni düzende yerel topluluklar, uluslaştırılan Hatay vilayeti ve yerel elitler; Hatay'da uluslaştırma ve dil üzerinden kimlik inşa faaliyetleri, farklılıkların diyarı Hatay: risklerden arınmış hoşgörünün ender bir örneği mi? Ek-1 ve Ek-2 sırasıyla "Görüşme Yapılan Kişilerin Listesi" ve "Sancak/Hatay Meselesinde Onde Gelen Kişiler Hakkında Bilgi" den terekküp etmektedir.

İşlenilen konular coğrafi konum, siyasi gelişmeler, ekonomik güç ve askeri birlik intikallerini kapsadığından, kitapta hiçbir harita, kroki, grafik, tablo, istatistik ve fotoğraf bulunmayışının izahı güç olsa gerekir. Bu yardımcı malzemenin kullanılmış olması 
halinde metnin kavranmasının kolaylaşacağı açıktır. Ek-l'de görüşüldüğü bildirilen kişilerin ad ve soyadlarının yazılmayıp sadece ilk harflerinin belirtilmesiyle yetinilmesine anlam verilememiştir. Yazar neden bu yola başvurduğuna dair herhangi bir açıklama yapmamaktadır. Akademik tarihyazımında somut kaynakların esas teşkil edip kimliği meçhul kimselerin kulak fisıltılarının değersiz sayıldığı bilim camiasının malumudur. Ek2'de Mustafa Kuseyri'ye yer verilmemesi yadırgatıcıdır. Kuseyri, Antakya'nın en büyük arazi sahibi Türk eşraf ailelerinden olup kendisi ve yandaşları yörede geniş nüfuz sahibi idi. 1936'da, daha önceki dönemlerdeki gibi, Şam'daki Suriye Meclis'ine Sancak'tan milletvekili seçilmiştir. Zamanında Suriye'de Iktisat Bakanlığı yapmıştır. Adıgeçen, Suriye yanlısı tutumuyla Sancak Türklerinin tepkisini şekmiştir. Gelişmeler sonunda 1938'de Türkiye lehine tavır almıştır.

Mehaz olarak Meclis Zabıtları dışında genelde kitap ve makale gibi ikinci el kaynaklar kullanılmış olup arşiv malzemesi ve yabancı basından yararlanılmamıştır. Cumhuriyet Arşivindeki kaynaklar konuların tahlili için yetersiz kalmıştır. 1918-1938 arasında Fransız işgali ve manda yönetimindeki İskenderun Sancağı ile 1938-1939'daki Hatay Devleti ve anavatana katılmadan sonraki dönemin ele alındığı bir eserde Başbakanlık Osmanlı Arşivi (BOA) ve Genelkurmay Askeri Tarih ve Stratejik Etütler Başkanlığı Arşivinin (ATASE) yanısıra Paris'teki Fransız Dışişleri ve Savunma Bakanlıkları Arşivleri ve Nantes'teki Fransız Yakın Doğu Manda Dönemi Arşivinde çalışmalar yapılmaması konuların tam genişlik ve derinlik kazanmasına izin vermemektedir. Milletler Cemiyeti Konseyi ve Daimi Mandalar Komisyonunun tutanakları ve diğer belgeleri incelenmemiştir. Bu nedenle BOA ve ATESE ile birlikte özellikle [Ministère des affaires étrangères. Series: Syrie-Liban Cabinet Politique ve League of Nations documents: Political Section and Mandates Section, Registry Files and External Fonds: Electoral Commission for the Sanjak of Alexandretta and Archives of the Special Tribunal (1919-1947)] fonlarının elden geçirilmesi zorunluluk arzetmektedir. Ayrıca, Fransa'nın 1938-1939'daki Dışişleri Bakanı Georges Bonnet'nin Défense de la Paix: De Washington au Quai d'Orsay, Fransa'nın 1939-1940'taki Ankara Büyükelçisi René Massigli'nin La Turquie devant la guerre: mission à Ankara (1939-1940), Fransa'nın 1939-1941'de Beyrut'taki Suriye ve Lübnan Yüksek Komiseri Gabriel Puaux'nun Deux Années au Levant: Souvenirs de Syrie et du Liban 1939-1940 adlı anı kitaplarına bakılmıs olması Hatay meselesindeki Fransız görüşlerinin daha etraflıca öğrenilmesine müncer olacaktır.

Metnin büyük bir kısmı tasviri nitelikte olup belge ve yayınların tahlili yapılmak yerine alıntıları verilmektedir. Sancak ve Hatay Devletindeki iç çekişme ve çatışmalar tam vuzuhla anlaşılamayacak tarzda genelleştirilmektedir.

Kitap pek çok yorum ve değerlendirme hatasıyla maluldur. Bunları şöyle sıralamak mümkündür.

Duman'ın, “Ískenderun Sancağında yaşayan Türklere yönelik Türkiye'nin izlediği politikanın ulusal sınırlar dışında kalan Türklerle ilgilenmeme siyasetine istisna teşkil ettiği” (s. 24) iddiası doğru değildir. Türkiye Cumhuriyeti kurulduğu tarihten beri dış Türklerle, imkanlar ölçüsünde, ilgilenegelmiştir. Bunun en bariz örneği Kıbrıs Türklüğüdür. Anavatanın Kıbrıs Türklüğüne ilgisi her daim baki olmuş ve halen de devam etmektedir. Şubat 1959 Zürih ve Londra Antlaşmaları ile Temmuz-Ağustos 1974 Kıbrıs Barış Harekatı bu bağın siyasi ve askeri alanlarda somutlaşmış şekilleridir. 
Yazarın 24. sayfada başlayıp kitabı boyunca tekrarladığı "Hatay'daki uluslaştırma" tezini kabul etmek zordur. Iskenderun-Antakya yöresi gerek fiziki özellikler ve coğrafya gerek nüfus ve kültür itibariyle Türk niteliğini yüzyıllardır korumuştur. Keyfiyet dönemin Türk bilim adamlarının yanısıra Fransız ve İngiliz tarihçilerince de teyit edilmiştir.'

Duman'ın "manda döneminde Sancak nüfusuna dair en güvenilir rakamların Fransız kaynakları olduğu" (s.127) beyanına katılmak asla mümkün değildir. Nüfus rakamları TürkFransız uyuşmazlığında hayati önemi haiz olduğu için meselenin tartışılmasına izleyen dört paragrafta geniş yer verilmiştir.

Fransa, Ana Müttefik Devletler Yüksek Konseyi kararınca 25 Nisan 1920'de San Remo'da Suriye manda yönetimini üstlendikten sonra, demografik veri toplanması konusunda savaş ve göçler nedeniyle çok olumsuz şartlarla karşı karşıya kalmıştır. Mahalli nüfus Fransız manda makamlarının gerçek niyetleri hakkında kuşku duymuş ve ülkedeki yabancı işgaline direnmiştir. Ahali değişik diller konuşuyor ve farklı itikatlara sahipti; siyasi ve dini rahatsızlık yaygındı, kontrol altında tutulacak geniş arazi vardı ve nüfusun bir kısmı yerleşik düzene geçmeyip göçebe ve yarı göçebe halinde yaşıyordu. Mamafih işe girişilmişti ve, Fransız manda yönetimi boyunca Sancak hakkında kesin istatistikler hiçbir surette toplanamamasına rağmen, bir ölçüde ilerleme kaydedilebilmiştir. Ahalinin sayısının ögrenilebilmesi için çaba harcanmış ve ahvali şahsiye servisleri, yukarıda belirtilen engellere rağmen, faaliyet alanlarını doğum, ölüm ve evlenme olaylarını kapsayacak şekilde tedricen genişletmeye çalışmışlardır. Bununla birlikte, kelimenin tam anlamıyla gerçek bir nüfus sayımı yapmak hiçbir zaman mümkün olmamışır. Mandater devletin yıllık raporlarında zikredilen rakamlar kısmi nüfus sayımı, tahmin veya ahvali şahsiye kayıtlarına dayanmakta idi. Doğru sayım yapılmasını imkansız kılan etkenlerin varlığından ötürü bu rakamlarda geniş bir hata ve belirsizlik payı vardı. Nitekim Fransa'nın Milletler Cemiyeti Daimi Mandalar Komisyonu nezdindeki temsilcisi Robert de Caix tam kesinlikle çalışmak için hazırlıklı olmayan ahvali şahsiye servisi ve diğer idari dairelerin bulunduğu bir ülkede sahih doğum ve ölüm oranları istatistikleri derlemenin güç olduğunu bildirmiştir. ${ }^{2}$ Bu nedenle anılan rakamlar gerek önem gerek mukayese bakımından çok değer taşımayan göstergeler olarak telakki edilebilir. Bundan başka, yıllık raporlarda yayınlanan rakamlar düzgün ve sistematik tarzda sunulmamakta ve yıllar arasında mukayese yapılmasına imkan vermemektedir. ${ }^{3}$

Özellikle ana Suriye ve özerk yörelerde ihdas edilecek temsili kurullar için seçimler yapılabilmesi amacıyla Fransızlar Sancak'ta ilk nüfus sayımı çalışmalarına 1921-1923'te girişmişlerdir. "Sayımın" yapılmasındaki tamamiyet Sancağın çeşitli alt yerleşim birimlerine göre değişiklik göstermiştir. Örneğin, ovalarda sağlanan doğruluk derecesini dağlık mıntıkalarda görmek mümkün olmamıştır. Göçebelere ve yarı göçebelere standart ölçü

1 Bakını, örneğin, Jacques Weulersse, "Antioche, essai de géographie urbaine", Bulletin d'Etudes Orientales, Vol.4 (1934), p. 4; Philip Graves, "The Question of the Alexandretta", The Nineleenth Century, Vol.124 (August 1938), p. 158.

2 League of Nations, Permanent Mandates Commission, Minutes of the Fifth Session (Extraordinary), 1924, p. 101.

3 Yücel Güçlü, The Question of the Sanjak of Alexandretta: A Study in Turkish-French-Syrian Relations (Ankara: Turkish Historical Society Printing House, 2001), pp. 28-29. 
uygulamak kabil olmamıştır. Bundan başka, bazı kişiler ya sayım kartlarından kurtulmak için, ya da idari tedbirlerin vergi veya askerlik amaçlarıyla ittihazından kuşkulandıklarından dolayı sayımdan kaçınmışlardır. Ahali, gerçekte, zorunlu askerlik hizmetinin ihdasından korkmuş gözükmüştür. Kısacası, yıllık raporlardaki bir takım müphem ve eksik formlarla verilen ayrıntılar ne ahalinin kesin toplam sayısının ne de, sonuç itibariyle, nüfus artışının sağlıklı tespitini mümkün kılmıştır. Tamamlanması iki yıl alan 1921-1923 sayımı doğru dürüst şartlar altında yapılmamış ve çok sıkı denetlenmemiş olup ahalinin hatırı sayılır bir kısmı özellikle askere alınma korkusuyla bu işlerden uzak durmuştur. Ahvali şahsiye kayıtlarının nüfus tahminlerine dayanan 1932 tarihli rakamları, yıllık raporlara göre, 1921-1923'dekilerden çok daha gerçeklere yakındır. 1921-1923'de kayıtlı mevcut (veya geçici olarak mevcut) ahali sayısı 212.000 iken 1932 'deki sayının 186.000 olması şayanı hayrettir. ${ }^{4}$

Sancağın Ankara Anlaşmasıyla Fransa'ya bırakıldığı 20 Ekim 1921'deki Türk tahminlerine göre, toplam nüfus sayısı 185.000 kadar olup bunun yaklaşık 100.000 'i Türk idi. Bu rakamlar büyük ölçüde Birinci Dünya Savaşının çıkışından önceki son, yani 14 Mart 1914'deki Osmanlı nüfus sayımından çıkarılmıştır. ${ }^{5}$ Bu rakamlar manda makamlarınca 1922'de 220.000'lik toplam nüfus içinde Türklerin sayısının yalnızca 87.000 'i bulduğu hakkındaki iddialardan çok farklıdır. Oysa, Fransa Sancağa özel yönetim rejimi imtiyazını vermesi fiilini 192l'de Ingiltere karşısında savunurken bu statünün "nüfusun çoğunluğunun Türkçe konuşması nedeniyle Türkçenin Fransızca ve Arapça ile aynı zamanda kullanılmasını öngördügünü" söylemekte beis görmemiştir. ${ }^{6}$ Bu itibarla Philip Graves gibi mesleki hayatının önemli bir kısmını saygın Ingiliz gazetesi The Times'ın Yakın Doğu muhabiri olarak geçiren bir gazetecinin "yörenin Türk niteliği hiçbir zaman sorgulanmamıştır ve hiç kuşku yok ki Birinci Dünya Savaşından önce Sancağın ahalisinin çoğunluğu Türklerden oluşmaktaydı" şeklinde yargıda bulunabilmesine şaşmamak gerekir.' 20 Ekim 1921'de Türklerin Sancak'ta çoğunluk teşkil ettiği yönündeki görüş İngiliz tarihçisi Albert Hourani ve Fransa'nın 19391940'daki Ankara Büyükelçisi René Massigli tarafından da paylaşılmaktadır. ${ }^{8}$

Anadolu'nun yüzyıllardır maliki olduklarından, Haçlıların sonundan beri hakim unsuru teşkil ettiklerinden ve 1516 'dan itibaren Suriye'yi egemenliklerinde tuttuklarından ötürü Türkler 192l'de, Sancağı sadece 25 Nisan 1920 tarihinde Suriye mandasının verilmesini takiben yönetmeye başlayan Fransızlardan daha doğru nüfus rakamlarına sahip olma konumundaydılar. Bundan başka, Fransız istatistiklerinin Arap iddialarının desteklenmesi yönünde ilgi duyulmaya başlanılan Birinci Dünya Savaşı sonrası dönemine ait olması da, bu rakamların doğruluğundan kuşkulanılmasına yolaçmaktadır.

4 Ibid., pp. 29-30.

5 Tableaux indiquant le nombre de divers éléments de la population dans l'Empire Ottoman au ler mars 1330 (Istanbul: Imprimerie Osmanié, 1919).

6 Great Britain, Treaty Series, Turkey No.1 (1922). Correspondence between His Majesty's Government and the French Government Respecting the Ankara Agreement of 20 October 1921. Cmd. 1570, London, 1922, p. 20.

7 Graves, "The Question of the Alexandretta", p. 158.

8 Albert Hourani, Minorities in the Arab World (New York: Oxford University Press, 1947), pp. 56-57; René Massigli, La Turquie devant la Guerre: Mission à Ankara (1939-1940) (Paris: Plon, 1964), p. 43. 
Duman, 2 Eylül 1938'de kurulan Hatay Devletinde yüksek mevkilere atamalarda yurttaşlar arasında ayrım yapıldığını ileri sürmektedir (ss.297-299). Uygulama bu iddianın sabit olmadığını göstermektedir. Bu kapsamda örnek olarak Harbiye ve Samandağ Belediye Başkanlıklarına yapılan atamalar zikredilebilir. İdari kadrolara atamalarda cins ve dil kıstasları yerine ehliyet ve liyakat esas alınmıştır. Memur, polis ve benzeri personel istihdamında yasa ve yönetmelikler çerçevesinde herkese eşit davranılmıştır.

Hatay'in 23 Temmuz 1939'da anavatana katılıp bir Türkiye Cumhuriyeti devleti ili olmasından sonra hükümetin eğitim faaliyetlerini her alanda yoğunlaştırması, Duman'ın eleştirel çekincelerine rağmen, memnuniyetle karşılanmalıdır (ss.373-378). Yurttaşa okumayazma ögretilmesi, eğitim imkanlarına kavuşturulması ve hayata daha iyi hazırlanmasının sağlanmasında bir olumsuzluk olduğu tasavvur edilemez. Türkiye'nin bir ili olmasını takiben Hatay'da Türkiye yasalarının yürürlüğe girmesinin siyasi ve sosyokültürel hayatta husule getirdiği yenilikleri de olağan görmek gerekir (ss.387-397).

Kitapta birçok konuya yeterince veya hiç değinilmemektedir. Örneğin, insan kaynaklarının gelişmesi ve toplumsal seyyaliyet bakımından hayati önem arz eden eğitim ve 1920 'den sonraki "kimliklerin" rolü gereğince tartışılmamaktadır. İskenderun Sancağ1 uyuşmazlığının sadece barış̧̧ı yöntemlerle değil aynı zamanda devletler hukukunun ilke ve kurallarına göre çözümlendiğinin üzerinde durulmaması, Hatay'ın anavatana iadesinin doğruluğu ve meşruluğunun devletler hukuku açısından uygunluğundan söz edilmemesi, 22 Temmuz-1 Ağustos 1938 seçimleri ve Hatay Devleti Meclisinin 29 Haziran 1939'da anavatana katılma kararının Amerika Birleşik Devletleri Cumhurbaşkanı Woodrow Wilson'ın plebisit ve kendi kaderini tayin ilkelerini yansıttığının ifade edilmemesi dikkat çekicidir.

Hatay'ın Türklüğünü üstü kapalı ve dolaylı şekilde sorgulamaya çabalayan "Vatan”ın Son Parçası Hatay'daki Uluslaştırma Politikalari'nda her ne hikmetse sonuç kısmı bulunmamaktadır. Öte yandan ve her şeye rağmen, Hatay ilinin "hoşgörü" diyarı olmanın ötesinde Türk milli birlik ve beraberliğinin timsallerinden birini teşkil ettiği meydandadır. Eğitim ve refah düzeyinin Türkiye genelinden yüksek olduğu yörede eskiden beri farklılıklardan ziyade ortak paydaların geçerli olduğu hususu unutulmamalıdır. 
